\title{
Former Effective Immunotherapy without Adverse Events of Inoperable Epithelial Ovarian Cancers and a Prospect for the Immune Prophylaxis
}

\section{Bukovsky $\mathrm{A}^{* 1}$ and Caudle $\mathrm{MR}^{2}$}

${ }^{1}$ The Institute of Biotechnology, Academy of Sciences of the Czech Republic, Prumyslova, Vestec at Prague, Czech Republic

${ }^{2}$ Cherokee Health Systems, Western Avenue, Knoxville, Tennessee, USA

${ }^{*}$ Corresponding author: Bukovsky A, M.D., Ph.D., D.Sc., Professor of Obstetrics and Gynecology, The Institute of Biotechnology, Academy of Sciences of the Czech Republic, Prumyslova 595, Vestec at Prague, 25250, Czech Republic, E-mail: abukovsk111@gmail.com, abu@tds.net

Citation: Bukovsky A, Caudle MR (2018) Former Effective Immunotherapy without Adverse Events of Inoperable Epithelial Ovarian Cancers and a Prospect for the Immune Prophylaxis. J Gynecol Res 4(1): 102. doi: $10.15744 / 2454-3284.4 .102$

Received Date: October 10, 2017 Accepted Date: April 09, 2018 Published Date: April 11, 2018

\begin{abstract}
Background: Current cancer treatments by immune checkpoint blockades are limited due to severe adverse events caused by alteration of the immune system required for homeostasis of normal tissues. Common cancer chemotherapy alters the quality of patients' lives. Platinum-based treatment can lead to severe neurotoxicity with chronic debilitation. Additionally, survival of patients with epithelial ovarian cancers (EOCs) has remained poor despite extensive cytoreductive surgery, high dose chemotherapy, checkpoint blockades and immunotherapies effective in some other types of cancer. The pathobiology of EOC cancer stem cells (CSCs) is not well understood. Observations demonstrate that EOCs exhibit in vivo two distinct CSC types - perivascular diploid CSCs dividing asymmetrically with the help of the host suicidal CD8+ T cells, and haploid CSCs at the cancer abdominal surface originating from meiosis I cytokinesis of bulk surface cancer cells. The perivascular CSCs contribute to the cancer cell bulk and, via left ovary venous blood, can cause EOC liver metastases. Haploid CSCs released from the bulk cancer surface cause the common pelvic and abdominal EOC spread. Former elimination of the host antibodies blocking $\mathrm{T}$ cell effectors by intermittent doses of cyclophosphamide exhibiting significant immunomodulatory anticancer effects, facilitation of the immune system reactivity against alloantigens of cancer cells by blood transfusions, and augmentation of anticancer immunity by bacterial toxins, resulted during the subsequent treatment-free period into rejection of inoperable EOCs without any adverse events during the treatnment. To help prevent cancer relapses, patients treated for advanced primary epithelial cancers should be considered as candidates for continuously stimulating immune anticancer activity by treatments such as daily metformin and weekly lentinan consumptions.
\end{abstract}

Conclusion: Given the poor outcomes of patients with advanced EOCs and former reports of successful treatments using immunologic enhancement, this area needs to be re-visited with modern clinical trials. Immune system preparations for EOC rejection without adverse events may be effective during subsequent treatment-free period, when the sensitized immune system is able without additional influences to reject cancer cells. The extended survival of cancer patients could be achieved by continuous use of substances maintaining long-term immune reactivity against cancer stem cells.

Keywords: Cancer Treatment Adverse Events; Tissue Homeostasis; Epithelial Ovarian Cancer; Cancer Pathobiology; Cancer Stem Cells; Effective Immunotherapy; Cancer Prophylaxis; Checkpoint Blockade; Checkpoint Inhibitors

List of Abbreviations: ASCD: Asymmetric Stem Cell Division; CSC: Cancer Stem Cell; DCD: Differentiating Cell Daughter; EOC: Epithelial Ovarian Cancer; MDC: Monocyte-Derived Cell; pMDC: primitive MDC; SCD: Stem Cell Daughter; STC: Suicidal T Cell

\section{Background}

Immune-related adverse events, ranging from mild to lethal, have been found to accompany immunotherapy with checkpoint inhibitors, but their underlying causes are not well understood [1]. Review of 22 clinical trials (1265 patients) with anti-CTLA-4 treatment indicated that the overall incidence of adverse events was $72 \%$, with high grade $24 \%$, and death occurring in $0.86 \%$ of patients. Adverse events included inflammation of gastrointestinal tract, skin lesions (rash, pruritus, and vitiligo), hepatitis, hypophysitis, thyroiditis, sarcoidosis, uveitis, Guillain-Barre syndrome, immune-mediated cytopenia and polymyalgia rheumatic [2]. Adverse events altering the quality of life can also be caused by the common cancer chemotherapy - nausea, vomiting, constipation, diarrhea, fatigue, hair loss, and mucositis [3]. Platinum-based chemotherapy may cause neurotoxicity and result in 
chronic debilitation [4]. Besides that, the survival of women with epithelial ovarian cancers (EOCs) has remained unsatisfactory during the last several decades [5,6]. Novel therapies without adverse events [7] and prevention of cancer recurrences are needed to improve treatment and long-lasting survival of patients with EOCs.

\section{Immune System and Tissue Homeostasis}

For effective cancer immunotherapy without adverse events, we need to better understand details of the immune system niche involvement in the homeostasis of all body tissues and the host immune niche support of cancer growth in vivo. T cells contribute to the asymmetric division (ASCD) of tissue stem cells during tissue regeneration. Along with monocyte-derived cells (MDCs), they also stimulate differentiation of postmitotic cell daughters into functional stages, the extent of which differs between certain tissue types, depending on the course of particular tissue differentiation during prenatal developmental immune adaptation [8]. The immune system belongs to a complex tissue control system [9] that includes vascular pericytes that accompany postcapillary venules. Pericytes stimulate the earliest differentiation of postmitotic tissue cells and proliferating endothelial cells, and their activity is regulated by perivascular autonomic innervation that also controls tissue quantity [10,11]. Autonomic innervation is absent in neovascularized primary [12] and metastatic [13] malignant tissues, where vascular pericytes exhibit extreme activity resulting in unlimited expansion of cancer cells and progressive vascularization [14]. Intraepithelial lymphocytes are permanently present in the skin, intestine, biliary tract, oral cavity, lungs, upper respiratory tract, and reproductive tract tissues [15]. The lymphocytes are also present in intermediate lobe of pituitary gland [16] and in liver sinusoids [17], They regulate thyroid hormone activity [18]. T cells play a role in local immune function and in differentiation of epithelial cells [19], and contribute to epithelial homeostasis [20-22].

Basic units of the tissue control system are associated with postcapillary venules (Figure 1 and 2), where primitive MDC (pMDC) interact with endothelial and tissue stem cells to enable their ASCD, if functionally required [11]. ASCD requires in vivo involvement of suicidal T cell (STC) giving rise to new stem cell daughters (SCD) and differentiating cell daughters (DCD) [14]. Suicidal lymphocytes have been identified in dividing cells of the mouse intestinal epithelium [23], and CD8+ STCs were identified during ASCD of ovarian stem cells within emerging new germ cells in adult human ovaries [24]. Host suicidal CD8+ T cells are also essential for the assymetric division of perivascular cancer stem cells (CSCs) - see below.
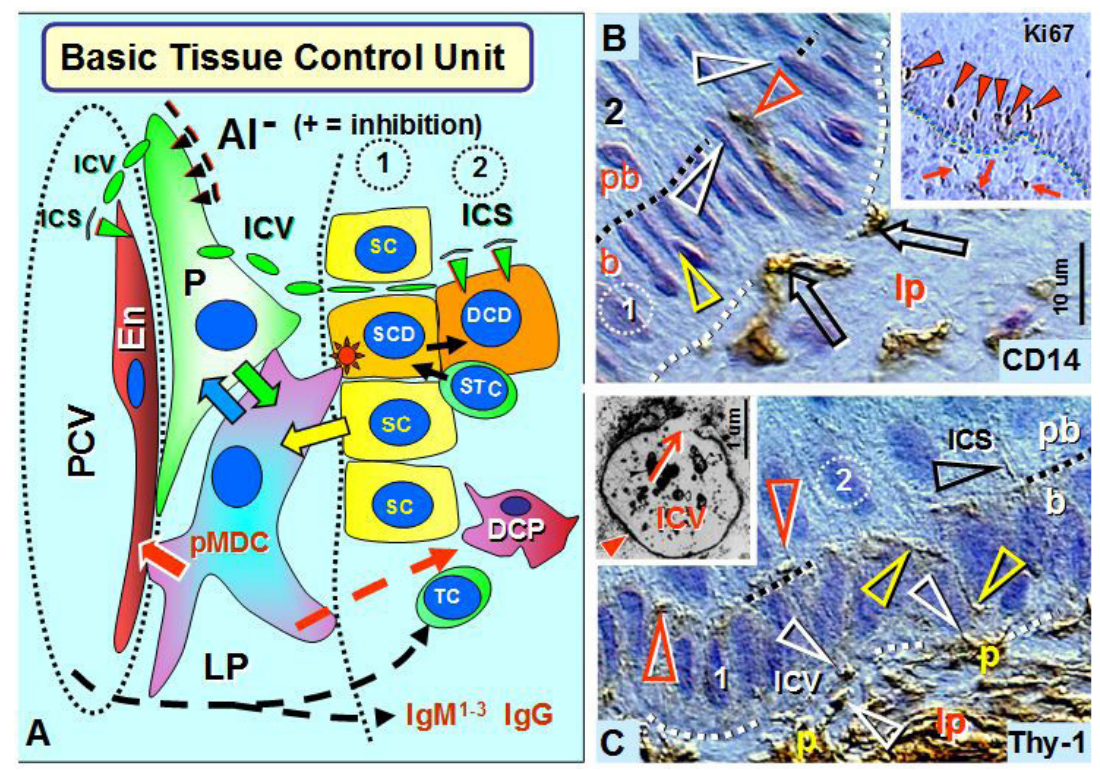

Figure 1: Basic tissue control unit and early differentiation of postmitotic tissue cells (A) Basic tissue control unit (TCU) is associated with postcapillary venule (PCV). The TCU consists of CD14+ primitive MDC (pMDC), pericytes (P) accompanying PCV, and autonomic innervation (AI) that controls pericytes and TCU activity to manage the tissue quantity. pMDCs are dominant components of the TCUs. They receive signals (yellow arrow) to regenerate from tissue stem cells (SC) when functionally required, and communicate with pericytes (blue arrow) whether their activity is not inhibited by AI. If not (green arrow), the pMDC stimulate asymmetric stem cell division (red asterisk) which is accompanied by a suicidal T cell (STC) that enters (black arrows) the SCD and DCD, where the STC degenerates (see Figure $5 \mathrm{C}$ for details in epithelial ovarian cancer). This gives a rise to the stem cell daughter (SCD) and differentiating cell daughter (DCD). The pericytes provide by Thy-1+ intercellular vesicles (ICV) growth factors and cytokines to stimulate differentiation of postmitotic DCDs and, if needed, to divided endothelial cells, e.g., during the growth of ovarian follicles. After release of ICV content (green arrowheads), the ICVs collapse into intercellular spikes (ICS). The pMDCs also communicate with endothelial cells (red arrow) to regulate influx of tissue-committed T cells (TC) and immunoglobulins ( $\left.\operatorname{IgM}^{1-3}, \operatorname{IgG}\right)$, depending on the pMDC properties outlined for the particular tissue during prenatal immune adaptation. Accordingly, some of pMDCs transform into dendritic cell precursors (DCP); (B) Some of the pMDCs in the epithelium lamina propria (lp) enter (arrows) basal epithelial layer (b), interact with basal epithelial stem cells (yellow arrowhead), and migrate to the inner parabasal layer (pb; red arrowhead). Postmitotic basal cells (white arrowheads) migrate to the parabasal layer. Arrowheads in the inset indicate Ki67+ postmitotic parabasal DCDs (note a lack of Ki67 expression in the corresponding basal SCDs); arrows indicate postmitotic DCDs in the lamina propria; (C) Thy-1+ pericytes (p) in the lamina propria produce ICV (white arrowheads), which migrate through the basal layer (yellow arrowheads) to the postmitotic parabasal cells (red arrowheads) to empty their content and transform into ICS (black arrowhead). Inset shows Thy-1 immunolabelling in transmission electron microscopy of the ICV that is releasing its content (arrow). Adjusted from $[8,11]:{ }^{\circ}$ Antonin Bukovsky 


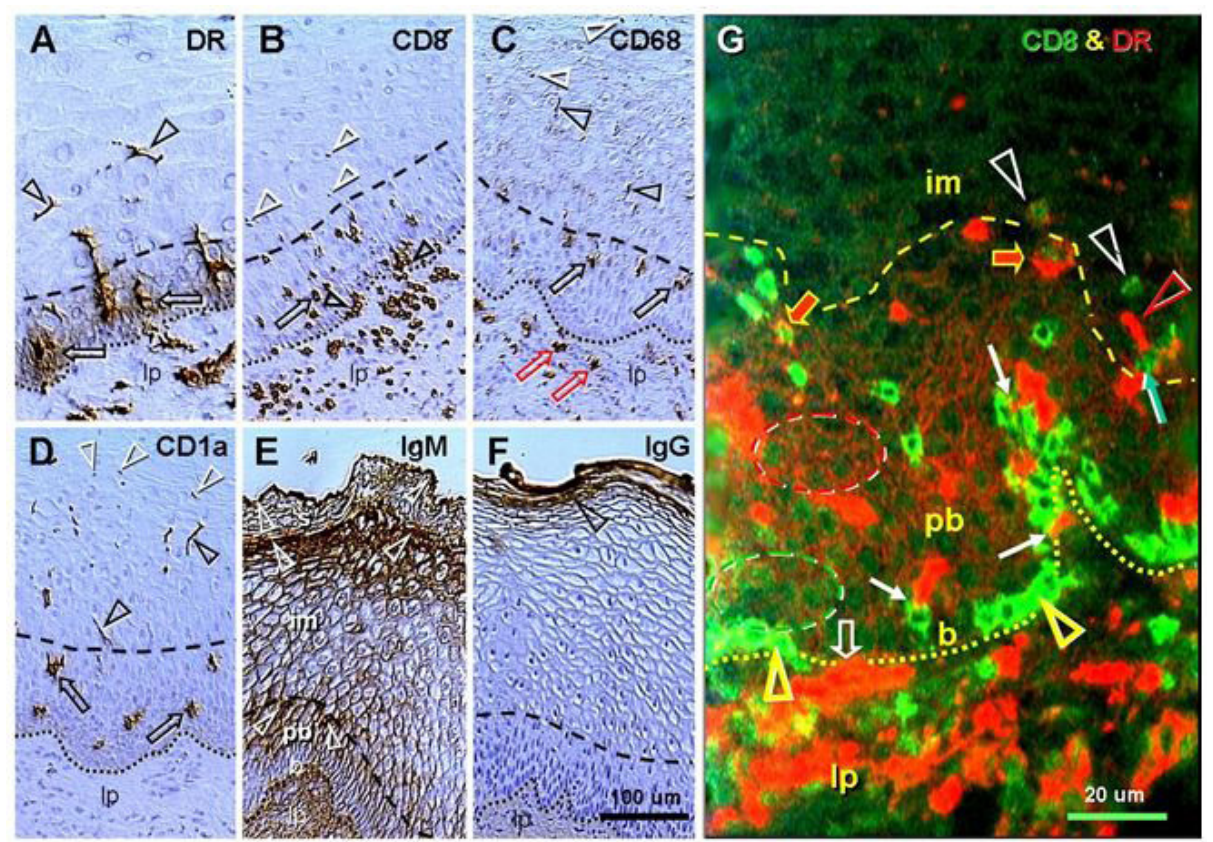

Figure 2: Differentiation and regression of MDCs and $\mathrm{T}$ cells, and binding of $\operatorname{IgM}$ and $\operatorname{IgG}$ in the squamous epithelium of the uterine ectocervix. (A) DR+ MDC release DR molecules in the parabasal layer (arrows) and transform into dendritic cells in the intermediate layer (arrowheads); (B) CD8 T cells migrate from lamina propria into the basal (black arrowheads) and parabasal (arrow) layers, and undergo apoptosis after entering the intermediate layer (white arrowheads); (C) The MDC express CD68 in the lamina propria (red arrows) and upper parabasal layer (black arrows) and CD68+ dendritic cells (black arrowheads) undergo apoptosis in the mid intermediate layer (white arowheads); (D) CD1a stains MDC in the parabasal layer arrows and dendritic cells in a similar manner as CD68. Note a lack of CD1a expression in the lamina propria; (E) IgM binds to the upper parabasal, intermediate and superficial layers (arrowheads); (F) IgG binds to the entire superficial layer. (G) CD8+ T cells (green) accumulate (yellow arrowheads) in the basal layer (b) and DR+ MDC (red) entering epithelium (open arrow) interact with $\mathrm{T}$ cells in the basal and parabasal (pb) layers (solid white arrows). At the parabasal/intermediate interface (dashed line), the T cells express DR (red arrows) indicating their activation. The $\mathrm{T}$ cells entering the intermediate layer (green arrow) cause differentiation of MDC into dendritic cells (red arrowhead) and degenerate (white arrowheads). Green dashed line ellipse indicates CD8 protein release from $\mathrm{T}$ cells among early differentiating parabasal cells, and red dashed line ellipse indicates DR release from MDCs among moderately differentiating parabasal cells. Adjusted from [8,11]: ${ }^{\oplus}$ Antonin Bukovsky

The immune system has been considered to provide organism protection against nonself substances and ignore self-tissues due to the elimination of autoreactive lymphoid cells $[25,26]$. This is an incorrect assumption for two reasons: $\mathrm{T}$ cells are required for the proper function of some body tissues (see above), and the autoimmunity is a consequence of an altered "stop effect" of pMDCs, either due to the altered tissue development during the prenatal immune adaptation (e.g. type 1 diabetes) [8], or due to the ageinduced regression of the immune system function [27]. This causes age-associate diseases in certain tissues (e.g. Alzheimer's disease) $[8,14]$. Beside their immune function, the CD8+ T cells play an important role in homeostasis of epithelial tissues by enabling as STCs the ASCD of epithelial stem cells in vivo, and also stimulating early differentiation of epithelial cells. While exhibiting gradual decline they also transform the MDCs into dendritic cells [14]. Figure 2G shows that the T cells accumulate among basal epithelial stem cells, where they participate in the stimulation of ASCD. They release CD8 among early differentiating parabasal cells, interact with MDC to stimulate their transformation into intraepithelial dendritic cells, and degenerate. The intraepithelial MDC release HLA DR protein among moderately differentiated parabasal cells, and dendritic cells regress among moderately differentiated cells in the intermediate layer. Hence T cells and MDCs interact and degenerate to stimulate regeneration and maturation of epithelial cells [8]. The regenerative renewal interval for intestinal cells is 2-4 days, 6 days in the ectocervix, 1030 days for epidermal cells, and 6 to 12 months for liver hepatocytes [28]. Therefore, the presence of suicidal CD8 T cells among tissue stem cells is more common in tissues with fast cellular regeneration, compared to the slower ones, e.g., intestinal cells vs. hepatocytes. During regeneration of the liver after partial hepatectomy, however, numerous T cells emerge to stimulate hepatocyte renewal, until the normal liver volume reappears [29].

CTLA-4 is expressed by both, CD4 and CD8 T cells [30]. Therefore, the immune-related adverse events accompanying CTLA4 blocking will predominantly affect tissues where $\mathrm{T}$ cells are involved in the stimulation of tissue regeneration by ASCD and in differentiation of postmitotic cells into the functional stages (compare the tissues altered by adverse events and permanent presence of $\mathrm{T}$ cells in tissues listed above). On the other hand, tissues lacking a permanent presence of $\mathrm{T}$ cells, like the brain, skeletal muscles or pancreas, are not as likely to be affected by CTLA-4 blocking. Their regeneration, however, will be altered, if it requires involvement of CD8+ STCs in the stimulation of ASCD of stem cells. 


\section{How to Treat Severe Immune-Related Adverse Events after Checkpoint Blockades}

It is apparent that adverse immune events after checkpoint blockades alter those tissues when committed T cells are required for their proper homeostatic function. It is possible that severe multiorgan adverse events, which may cause the patient's death, can be treated by blood transfusion from the young healthy donors of the same sex and ethnicity, as proposed for the treatment of ageassociated diseases [14]. This can cause functional repair of tissues requiring committed T cells for regeneration by ASCD from their stem cells and for differentiation of DCDs into the functional stages. The effect of such treatment in affected patients can last till the regeneration of the recipient's own immune system homeostatic effectors regulating the regeneration and function of dependent tissues, as blood mononuclear cells have been found to survive in trauma-affected blood recipients for 6 to 18 months [31] or longer, due to the transfusion-associated microchimerism [32,33].

\section{Why do Epithelial Cancer Cells Grow in Immunocompetent Mammalian Organisms?}

The growth of epithelial cancers has been suggested to be due to the ability of cancer cells to utilize conditions similar to those required for survival of semiallogeneic embryos in mammalian pregnancies [34]. Human and mouse cancer cells express allogeneic class I and class II MHC determinants [35,36]. Hence, host support of cancer growth is comparable to the support of semiallogeneic (or allogeneic in the donor egg recipients) mammalian embryo implantation and growth. During implantation, the embryonic trophoblast hybridizes with the uterine epithelium [37]. Feto-placental vessels lack innervation, hence control of this circulation is dependent on both locally produced and circulating vasoactive factors [38]. The difference between blood vessels in tumors and normal tissues has been recognized for a long time. Tumor endothelium is proliferating 20 to 2000 times faster than that of any normal tissue endothelium in adult individuals, except in the placenta, which has an even faster endothelial proliferation [39].

\section{Host Support of Epithelial Ovarian Cancer Growth}

Cells of epithelial cancers express macrophage antigens [34,40] due to hybridization with the host pMDCs [14] - (Figure 3). Immunohistochemical study of EOCs demonstrates staining for MDC markers in cancer cells adjacent to the microvasculature, except for their stem cells (Figure 4A,C,D and E). Dashed line ellipses in Figure 4B show Ki67 expression by pairs of divided cancer cells distant from the cancer microvasculature. The observations above (see inset in Figure 1B) indicate that the Ki67 is expressed by postmitotic DCDs, but not by the corresponding SCDs. However, pairs of spermatogonial and oogonial stem cells undergoing meiosis I symmetric division (cytokinesis) exhibit strong Ki67 expression in the monkey testes and ovaries [41]. Therefore, the Ki67 staining of cell pairs in the Figure 4B indicates pairs of haploid malignant cells formed during the meiosis I of ovarian stem cells [42]. The generation of the haploid cells in meiosis I is supported by cancer/testis SCP-1 protein that was identified in malignant gliomas, breast, renal cell, and ovarian cancers. SCP-1 has been proposed to contribute to genomic instability of such malignant cells [43]. The occurrence of cancer cell divisions at the surface of the EOC tumor bulk contributes to their release into pelvic and abdominal cavities and the common development of EOC metastases. The left ovarian vein often drains into the left renal vein [44] contributing the liver veins, and perivascular CSCs released into the postcapillary venules can often cause liver metastases.

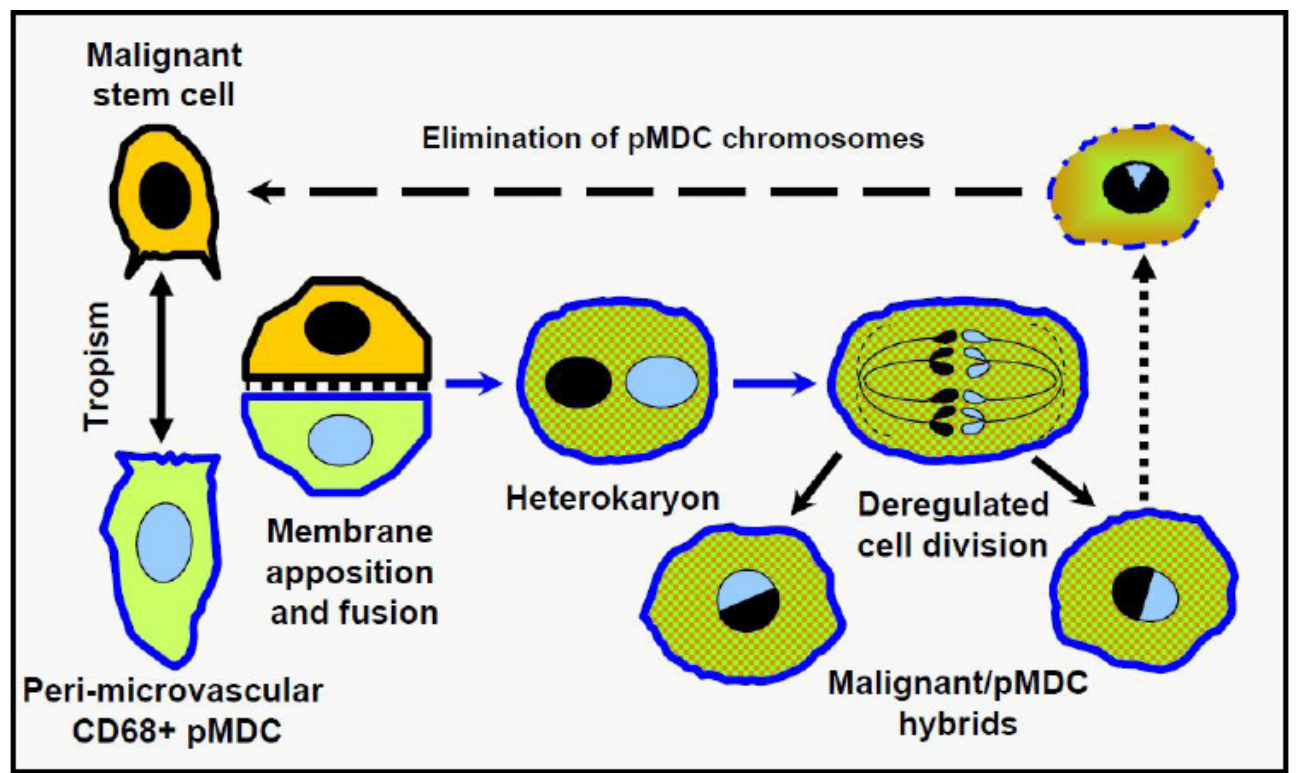

Figure 3: Hybridization of malignant stem cells with the host microvascular pMDC; Scheme of the fusion between cancer stem cell and microvascular MDC causing the development of hybrids with surface and cytoplasmic expression of MDC markers and preservation of malignant potential. Occasional elimination of normal chromosomes results in hybrid reversal back to the malignant stem cell. Adjusted from [11]: ${ }^{\bullet}$ ntonin Bukovsky 




Figure 4: Hybridization of cancer cells with diploid perivascular CSCs and development of haploid CSCs at the cancer bulk surface. (A) Cancer microvasculature (mv) is accompanied by unstained CSC (asterisk) and CD14+ MDCs (M). Adjacent cancer/MDC hybrids are densely stained (white arrowhead), more distant cancer cells show regression of cytoplasmic staining (arrow), and some of them lose CD14 marker and revert into dividing unstained CSCs (red arrowhead); (B) Parallel section shows microvasculature accompanied by Ki67+ postmitotic MDCs (black arrowheads), proliferating vascular endothelium (red arrowhead), and distant Ki67+ pairs of cancer cells (red dotted line ellipses) after their meiosis I division (see text) red arrow indicates Ki67+ cancer cell migrating toward the cancer bulk surface; (C) Parallel section shows marked DR staining of perivascular pMDC (M) releasing DR that binds to the adjacent cancer cells. The distant cancer cells are unstained and some of them represent Ki67+ postmeiotic cancer cells (see panel B); (D) The CD68 is expressed on perivascular MDC. Cytoplasmic and surface staining is abundant on the cancer cells (asterisks) in the tumor mass; (E) Detail from panel D shows unstained postmitotic CSC daughters represented by the stem cell daughter (SCD) and "differentiating" cell daughter (DCD). The DCD (dotted red line) associates with a perivascular pMDC during initiation of cancer cell hybridization by membrane apposition (white arrows). Two previously formed early hybrids (EH) originating from deregulated cell division of the binuclear hybrid cell (heterokaryon in Figure 3), show perinuclear staining only. More advanced hybrid (H) shows almost complete cytoplasmic expression of CD68 MDC marker. Unstained dividing CSC (yellow dotted line) is in telophase with reappearance of the nucleoli (arrowheads). Red arrow indicates more dense cytoplasm in one of the emerging daughter cells - compare with the presence of intracytoplasmic CD8+ T cell in the inset of Figure 5A and cancer "differentiating" cell precursor (CDCp) containing the host STC in Figure 5A. Adjusted from $[8,14]:{ }^{\circledR}$ Antonin Bukovsky

Figure 4E (detail from panel D) shows membrane apposition between the cancer DCD and perivascular host MDC during the formation of the cancer DCD/host MDC hybrid (Figure 3). Hybridization with the host pMDCs allows cancer cells to utilize the dominant role of pMDC in the management of tissue homeostasis and vascular growth (see Figure 1). Also shown is a dividing unstained CSC exhibiting denser cytoplasm in one of its developing daughters (red arrow). The inset in Figure 5A shows dividing CSC containing STC in one of the emerging daughters, resembling the situation during ASCD in the adult human ovary [45]. The cancer DCD containing STC contribute to the unlimited grow of cancer cell bulk and the cancer SCD will divide asymmetrically again after interaction with another host STC (see the yellow arrowhead in the Figure 5A). The vascular extension in growing cancers is caused by the lack of vascular autonomic innervation. This is accompanied by extreme activity of vascular pericytes in producing Thy-1+ intercellular vesicles (Figure 5B - compare with Figure 1C showing moderate activity of pericytes in the normal epithelium), which stimulate early development of postmitotic cancer DCDs and differentiation of endothelial cell sprouts for vascularization of expanding cancer cell mass. 

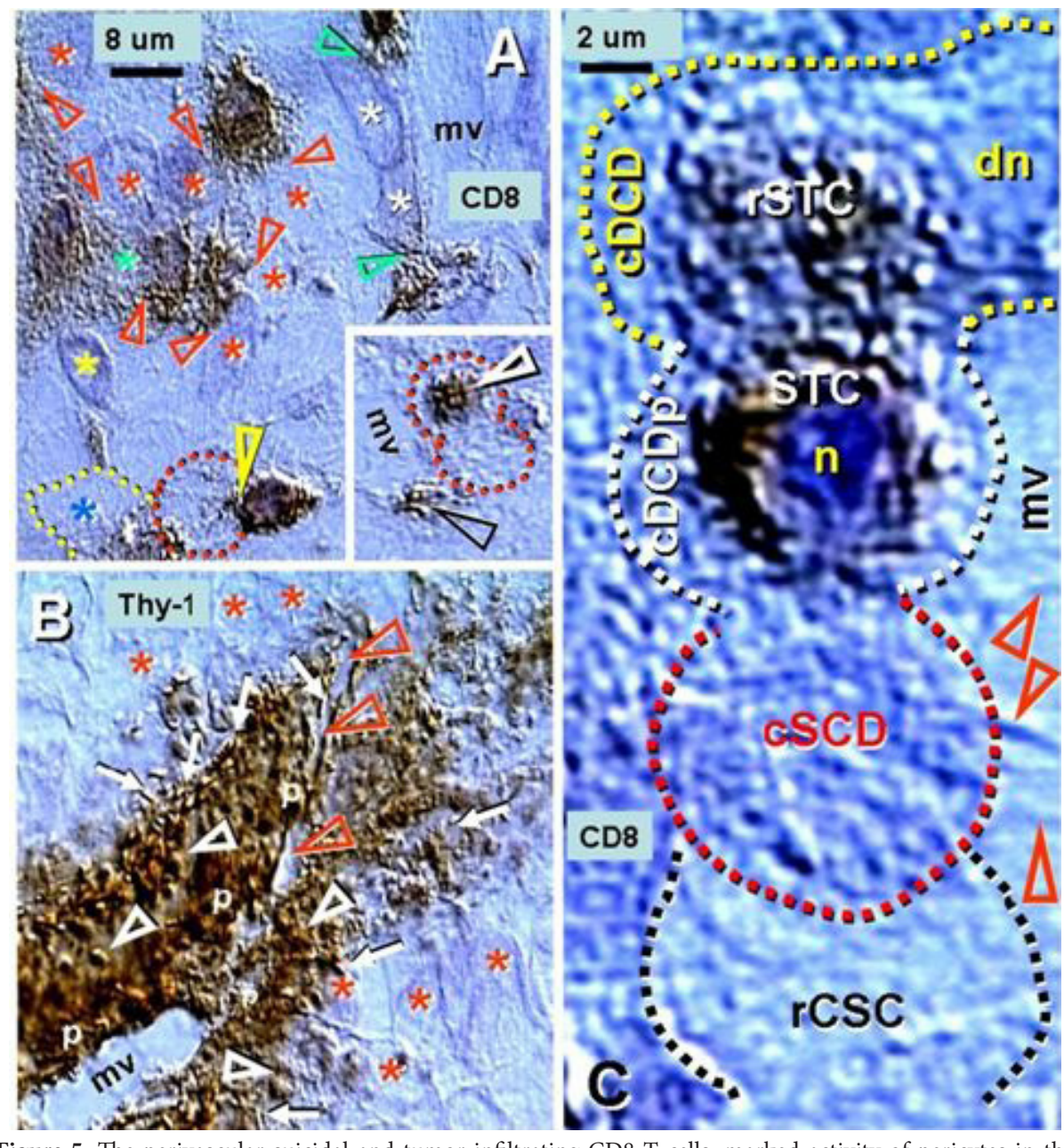

Figure 5: The perivascular suicidal and tumor infiltrating CD8 T cells, marked activity of pericytes in the advanced EOCs, and $\mathrm{T}$ cell involvement in the asymmetric division of cancer stem cell. The CD8 T cells invade from microvasculature and interact (green arrowheads) with adjacent perivascular CSCs (white asterisks) to stimulate their asymmetric divisions. Distant $\mathrm{T}$ cells increase in size when accompanying (red arrowheads) "differentiating" cancer cells (red asterisks). Green asterisk indicates CD8 staining of the early "differentiating" cancer cell and yellow asterisk indicates fresh DCD joining the cancer cell bulk. The CSC (dotted red line circle) is entered (yellow arrowhead) by CD8+ STC, and previously formed cancer DCD (blue asterisk and yellow dotted line) contains CD8+ remnants ( $r$ ) of regressed host STC. Panel A inset shows asymmetric division of perivascular CSC marked with red dotted line. The cytoplasm of one daughter cell is occupied by a suicidal T cell (white arrowhead). The occupied daughter cell is expected to contribute as DCD to the larger cancer cells in the tumor mass (see yellow asterisk in panel $\mathbf{A}$ ) and the SCD will remain at the perivascular site to be ready to divide asymmetrically again after interaction with $\mathrm{T}$ cells evading from the blood circulation. Black arrowhead in the inset indicates CD8+ remnants of STC from the former CSC asymmetric division; (B) Thy-1 pericytes (p) accompanying cancer microvasculature exhibit extreme activity in producing Thy-1+ intercellular vesicles (white arrowheads), which collapse into intercellular spikes (arrows) after releasing their content stimulating growth of cancer cells (asterisks) - compare with moderate pericyte activity in the normal epithelial tissue in Figure 1C. Red arrowheads indicate proliferation of endothelial cells preparing the vascular extension for the support of an unlimited cancer growth due to the lack of autonomic innervation controlling the pericyte activity; (C) The CSC asymmetric in vivo division repeatedly utilizes circulating CD8+ host T cells to produce cancer "differentiating" cell daughters. The former CSC regresses (rCSC) after producing cancer SCD ( $\mathrm{CSCD}$ ) and cancer "differentiating" cell daughter precursor (CDCDp) with the help of CD8+ host STC transferred from regressing CSC to the DCDp. The postmitotic cancer DCD ( $\mathrm{CDCD}$ ) containing developing nucleus $(\mathrm{dn})$ and regressing STC (rSTC) is formed prior to separation of $\mathrm{CDCD}$ from the ongoing new CSC asymmetric division. Arrowheads indicate $\mathrm{CSCD}$ extensions into the microvasculature (mv) to attract the host $\mathrm{T}$ cells for another cancer ASCD. Adjusted from $[8,14]:{ }^{\bullet}$ Antonin Bukovsky

Figure 5C shows detail of CSC asymmetric division in the EOC. The cancer ASCD is a highly complex process consisting of several distinct cell stages that include regressing former CSC, developing new cancer SCD that exhibits extensions into the adjacent microvasculature to attract new host CD8+ STC for dividing asymmetrically again, cancer DCD precursors containing vital host CD8+ STC with the nucleus, and a new cancer DCD with developing nucleus and remnants of the regressing CD8+ STC. The observation of the complex events during asymmetric division in EOC indicates similarity to the events occurring during cellular regeneration in normal tissues. Growth of colorectal cancer exhibits properties that markedly resemble those in the normal intestinal epithelial stem cells [46]. Although only limited data are available on the modes of division used by adult mammalian stem cells in vivo [47], the main difference is that the regeneration of normal adult tissues is quantitatively controlled 
by the perivascular autonomic innervation and terminated when the limit is reached [14], but "regeneration" of cancer cells in vivo is endless, as perivascular autonomic innervation is absent in both primary and metastatic malignancies [12,48].

From this point of view, the therapeutic effect of immune check point blockades may lie in causing the in vivo inability of the perivascular CSCs to divide, due to the lack of assistance of the host's STCs. This causes a marked alteration in the cancer pathobiology due to the lack of postmitotic cancer DCD development and hybridization with the host perivascular pMDCs. Consequently, host perivascular pMDCs may convert into anticancer effector macrophages eliminating the perivascular cancer stem cells. Tumor infiltrating T cells stimulating differentiation of postmitotic cancer DCD may convert into cytotoxic effectors causing regression of cancer cells. The disadvantage of checkpoint inhibitors for therapy of EOCs is that the EOCs have two distinct types of cancer stem cells. The haploid cancer stem cells are not T-cell dependent and can proliferate later, when the checkpoint inhibitors are depleted, with preservation in the ascites and tumor in the pelvic and abdominal cavities. The same may apply for some malignancies expressing the cancer/testis SCP-1 protein, like malignant gliomas and breast and renal cell cancers [43].

The common chemotherapy directly targets the cancer cells based on the in vitro effects, without dealing with the host support of cancer growth. Nevertheless, the chemo-immunotherapy reviewed below did not exhibited any adverse events accompanying current immunotherapy or chemotherapy.

\section{Two Distinct Cancer Stem Cell Types in Pathobiology of EOCs}

It is generally believed that a single type of ovarian CSC exists, which is capable of unlimited self-renewal and differentiation. The CSCs represent about $0.01-1 \%$ of malignant ovarian cells [49-53]. Although a recent article reviewed the in vivo role of the ovarian CSC niche [54], the specific involvement of the vascular pericytes, pMDCs and CD8+ STCs in the in vivo management of perivascular CSCs has not been delineated. Our observations above indicate that the pathobiology of EOCs, and possibly of some other cancer types expressing SCP-1 protein, is more complex in vitro and based not on a single uniform ovarian CSCs, but on two distinct CSC types, the diploid CSCs undergoing ASCD with the help of the host CD8 T cells at the perivascular regions, and haploid CSCs evolving at the intraperitoneal surface of the cancer cell bulk. During ASCD of the ovarian CSCs, one of the CSC daughters will evolve into the new CSC and the other containing STC will evolve into cancer DCD, like in normal epithelium, but with malignant potential. Cancer DCDs hybridize with perivascular MDCs and join the tumor cell mass, where their "differentiation" and enlargement is stimulated by infiltrating CD8+ T cells. Tumor growth is enhanced by the permanent supply of hybridized postmitotic cancer DCDs. The malignant potential of cancer cells in the tumor exists due to the fact that they lose MDC chromosomes, reverting back to CSCs (Figure 3 and 4A). Additionally the EOC cells distant from microvasculature exhibit meiosis I cytokinesis resulting in two haploid cancer cells (Figure 4B), which contribute to the additional genomic instability of the malignant cells. Haploid cancer cells (27 chromosomes) were detected in epithelial lung cancer that exhibited in vitro hyperploidy with 54 chromosomes [55]. This indicates that haploid EOC cells released from the tumor surface into the abdominal ascites can transform into diploid CSCs and implant to form pelvic and abdominal metastases. Normal ovarian meiosis I events lead to development of two identical haploid cells by symmetric division, with Ki67 expression in both. This contrasts with the ASCD of normal epithelial cells, where SCDs emerge without Ki67. Meiosis I cytokinesis occurs during the development of the new germ cells from the ovarian stem cells in ovarian surface epithelium, in both the adult young and aged human ovaries [42]. Ovarian surface epithelial cells are the most common potential source of EOCs, probably due to the genomic instability of haploid germ cells developing during meiosis I in aged women. In young women the haploid germ cells enter the ovarian cortical veins and are either associated with perivascular granulosa cell nests to form the new primary ovarian follicles, or quickly eliminated in the ovarian medullary vessels [14]. Such event may be absent in older women due to age-related depletion of the immune system reactivity [27] required for the elimination of superfluous germ cells. The existence of two distinct CSC types in EOCs, and the presence of possibly chemotherapy-resistant haploid CSC in the abdominal cavity in particular, may contribute to persistence and clinical recurrence of malignancy after primary EOC treatments.

\section{Lessons from Early Immunotherapy Experiments}

William B. Coley, the bone sarcoma surgeon, considered to be a "father of immunotherapy", had the idea of stimulating the immune system to reject human cancer cells by injecting streptococcal bacteria into cancer patients. This was met with an apparent success [56,57]. In the 1970s, a set of experiments involving immunotherapy of cancer provided several important results. Patients with growing cancer had circulating lymphocytes capable of killing in vitro their own malignant cells, but this effect was prevented in vivo by host circulating antibodies, which blocked effector T cells from killing the malignant cells [58,59]. This serum blocking activity was eliminated by cyclophosphamide [60]. A single cyclophosphamide intravenous injection combined with intradermal injection of Corynebacterium parvum toxins resulted in fibrosarcoma regression in 70 percent of the treated mice. Lengthening this treatment caused an increased survival time of the animals [61]. The injection of allogeneic spleen cells sensitized in vitro caused rejection of tumor allografts [62], suggesting that the stimulation of the immune system alloreactivity was beneficial. Additionally, BCG vaccine alone had prophylactic and therapeutic effects against the growth of transplanted experimental sarcomas [63].

\section{Advanced and Recurring Ovarian Epithelial Cancers are Resistant to Successful Current Treatments}

Antibody-based therapies, immune checkpoint blockades, cancer vaccines, and chimeric antigen receptor-modified T cells have 
all shown some preclinical success and have had clinical trials [64]. Survival of women with EOCs, however, remained poor [5], despite extensive debulking surgery and high dose cytostatics and the treatment of recurring ovarian cancer continues to be elusive [65]. Management of EOCs still mainly consists of cytoreductive surgery and platinum-based chemotherapy. While clinical remissions are obtainable, approximately $70 \%$ of patients will relapse and die of disease within the 5 years [66]. Antibody blockade of the T cell molecule CTLA-4 unleashed the body's immune response against malignant tumors. This concept has led to the development of "immune checkpoint therapies" that may prolong the lives of some cancer patients [67]. Emerging clinical data, show limited clinical efficacy of these agents in ovarian cancers, with objective response rates of 10-15\% only [68].

\section{Regression of Inoperable EOCs after Chemo-Immunotherapy without Adverse Events}

Due to the current poor outcomes with conventional treatment of advanced to EOCs and the serious complications of these therapies, successful former cases employing chemo-immunotherapy without any adverse complications in two advanced EOCs is reviewed. The treatment was based on a series of cancer-related experiments reported in 1970s (see above).

\section{Survey of Patient 1 Treatment, 61 Years Old}

April 25, 1976: Before treatment, the patient was in a reactively good physical condition, without evidence of cachexia, and had only a moderate constipation problem. Red and white blood cell counts were normal, but the sedimentation rate was higher (57/90). Explorative laparotomy, performed for painful tumor mass in the left subchondrium in our gynecologic clinic at the Institute for the Care of Mother and Child, Prague, Czechoslovakia, had shown complete infiltration of the pelvis, generalized metastases in the abdominal cavity, and infiltration of the liver with massive metastases of ovarian carcinoma. The surgeon was even unable to perform a palliative colostomy due to the massive convolute of the gut with omentum and stomach, and expected that the patient would not survive 14 days. From the abdominal cavity 2.5 liters of the amber color ascites was removed. Histology of ovarian biopsy showed poorly differentiated papillary adenocarcinoma.

After the surgery and a mutual discussion, based on the serious conditions of the case and a review article on experimental studies of cancer treatment published a year ago [69], it was decided to attempt an unusual approach. Instead of common therapy with high doses of cytostatics alone, which were not likely to be effective, it was decided to attempt to induce the patient's immune system anticancer reactivity by several methods. Treatments consisted of placental blood-derived IgG, moderate doses of cyclophosphamide, allosensitization with blood transfusions against alloantigens of cancer cells, and stimulation of the immune system reactivity by high titers of Bacterinum adnexitidicum (BA)/SEVAC (also known as Adnexba) containing toxins from Enterococci, Escherichia Coli, Neisseria Gonorrhoeae, Staphylococcus Aureus, and Streptococci. Adnexba was formerly used for immunotherapy of acute human female pelvic inflammatory diseases [70]. The $3.8 \mathrm{ml}$ of IgG, commercially separated from the retroplacental blood and expected to contain unblocking antibodies [71], was injected intramuscularly the first day after the surgery, followed the next day by $1.9 \mathrm{ml}$ and intravenous injection of $400 \mathrm{mg}$ cyclophosphamide. Three days and ten days after surgery the patient received blood transfusions to stimulate immune system alloreactivity, and high titers of Adnexba were injected intradermally two to three times a week. Two weeks after explorative laparotomy the patient was released to come once a week for intradermal injections of Adnexba. Two months after explorative laparotomy the oral use of 50 mg cyclophosphamide tablet each day for a period of four weeks, combined with weekly injections of bacterial toxins, was begun. Ten weeks after explorative laparotomy a fist size tumor was still detected in the left subchondrium but no ascites. After finishing the cyclophosphamide treatment, it was decided to discontinue all anticancer therapy.

By two weeks a relatively prompt tumor regression in the left subchondrium had occurred. Six months after surgery a normal liver size was noted, and irrigoscopy demonstrated normal conditions of the colon. A "second look" surgery was performed. During relaparotomy the surgeon found the gut convolutions movable and entirely free of adhesions, and the peritoneum smooth. The pelvic cavity was blocked by coalescent remnants of the cancer process, exhibiting blue/brownish transparent cystic formations. The liver had regenerated into a normal healthy condition, without palpable metastases. The rectum exhibited several wrinkled nodes. A hysterectomy with salpingo-oophorectomy was performed. At this time the ovarian histology showed shrinking residual malignant adenocarcinoma with vigorous foci of degenerating malignant tissue. No evidence of fresh malignant growth was found. One week after the second look surgery the patient received a single blood transfusion, and was considered to be cured. Five months after surgery the patient absolved a balneotherapy in the warm mineral springs. A month later manifestations of constipation and signs of cancer recurrence in the abdominal cavity recurred. Treatment with the cyclophosphamide tablets alone was without results, and the patient soon died of a massive pulmonary embolization. An autopsy showed a marked recurrence of malignancy in the abdominal cavity [72]. The course of patient's hospital cancer treatment is summarized in Table 1.

\begin{tabular}{|c|c|}
\hline $\begin{array}{c}\text { Days since ex- } \\
\text { ploratory } \\
\text { laparotomy }\end{array}$ & Case treatment course \\
\hline 0 & Explor. laparot.: $2.5 \mathrm{~L}$ of ascites drained \\
\hline 1 & IgG $3.8 \mathrm{ml}$ i.m, \\
\hline 2 & IgG $1.9 \mathrm{ml}$ i.m, CF $400 \mathrm{mg}$ i.v. \\
\hline 3 & 1st BT $500 \mathrm{ml}$ \\
\hline
\end{tabular}




\begin{tabular}{|c|c|}
\hline $\begin{array}{c}\text { Days since ex- } \\
\text { ploratory } \\
\text { laparotomy }\end{array}$ & Case treatment course \\
\hline 13 & 2nd BT 500 ml, BA i.d. 2 times a week \\
\hline 14 & $\begin{array}{c}\text { Released from hospital. Occurred once a } \\
\text { week for BA i.d. application }\end{array}$ \\
\hline 60 & $\begin{array}{c}\text { CF 50 mg tablets daily for 28 days and } \\
\text { BA i.d. once a week. }\end{array}$ \\
\hline $88-183$ & No therapy \\
\hline 102 & $\begin{array}{c}\text { Sudden regression of abdominal tumors } \\
14 \text { days since beginning of no therapy } \\
\text { period }\end{array}$ \\
\hline 184 & Irrigoscopy: regular findings \\
\hline 188 & $\begin{array}{c}\text { Second look laparotomy with } \\
\text { hysterectomy \& adnexectomy }\end{array}$ \\
\hline 196 & BT 500 ml \\
\hline
\end{tabular}

List of Abbreviations: IgG: Immunoglobulin G; BT: Blood transfusion; BA: bacterinum adnexitidicum; CF: cyclophosphamide Table 1: Survey of patient 1 inoperable EOC treatment

Even though regression of advanced cancer was attained, we were unable to prevent its relapse. This lead to skepticism about the value of the immunotherapeutic approach, but eventually thoughts turned to analyzing what had caused the cancer regression and what possible errors resulted in its recurrence. It was speculated that one of the possible causes of relapse was the second look surgery with hysterectomy and salpingo-oophorectomy while there was ongoing cancer regression. Possibly the patient needed more than only subsequent blood transfusions. The recurrence was also treated only with cyclophosphamide without bacterial toxins and allosensitization. The warm spring balneotherapy might have also contributed to the initiation of the EOC relapse.

\section{Survey of Patient 2 Treatment, 63 Years Old}

In June 1985, a 63 year old woman presented with marked ascites. A high sedimentation rate (73/139) was detected. On August 15 , an explorative laparotomy was performed for excessive ascites and a distinctive retrovaginal mass on examination. A malignant ovarian mass involving a large amount of the abdominal cavity was discovered, and 6 liters of ascetic fluid was removed. Histology showed a poorly differentiated solid ovarian carcinoma. The $3.8 \mathrm{ml}$ of retroplacental IgG was injected intramuscularly at first day after surgery, followed the next day by $1.9 \mathrm{ml}$. Two weeks after laparotomy cyclophosphamide 400 mg was injected intravenously. Two days later weekly intradermal allosensitization using $0.5 \mathrm{ml}$ of lympho-leukocytic concentrate (allogeneic blood buffy coat) mixed with the high titers of bacterial toxins was initiated. After the first allosensitization combined with bacterial toxins, the patient had an expected strong reaction with fever, but subsequent applications were without any apparent effects. Three weeks after laparotomy, another 6 liters of ascetic fluid were drained. The first blood transfusion was performed two weeks later. At this time ascites was again present, but less than before. No drainage was performed. A second blood transfusion of $250 \mathrm{ml}$ was performed 10 days later, and from the remaining $250 \mathrm{ml}$ of blood the white blood cell buffy coat was collected for the continuation of allosensitization. The patient's blood counts remained in normal ranges, and the sedimentation rate was significantly lower (30/57) compared to that before treatment. Weekly therapy with the high doses of bacterial toxins continued after release from the hospital. Two and half months after laparotomy, a small amount of ascites was still present and $0.5 \mathrm{ml}$ of allogeneic buffy coat was injected intradermally. At this time daily cyclophosphamide tablets were set at $50 \mathrm{mg}$ for 4 weeks without injections of bacterial toxins. The blood smears showed the marked depletion of lymphocytes. Subsequently the ascites increased, and 8 liters of yellowish ascetic fluid were drained. Ten days later three more liters were removed. $0.5 \mathrm{ml}$ of allogeneic buffy coat was injected intradermally. In the next ten days ascites remained unchanged, and $0.5 \mathrm{ml}$ of allogeneic buffy coat mixed with bacterial toxins was injected intradermally to both groins. One month later, without any further therapy, the abdomen was soft, ascites undetectable, and no abdominal or pelvic mass was palpable. The previous month's exact treatment was repeated. Further information on this patient is not available [72]. The patient's course of hospital cancer treatment is summarized in Table 2.

\begin{tabular}{|c|c|}
\hline $\begin{array}{c}\text { Days since } \\
\text { exploratory } \\
\text { laparotomy }\end{array}$ & Case treatment course \\
\hline 0 & Explor. laparot.: 6 L of ascites drained \\
\hline 1 & IgG $3.8 \mathrm{ml}$ i.m. \\
\hline 2 & IgG $1.9 \mathrm{ml}$ i.m \\
\hline 14 & CF $400 \mathrm{mg}$ i.v. \\
\hline 16 & $\begin{array}{c}\text { Allogeneic Buffy Coat (ABC) } 0.5 \mathrm{ml} \\
\text { mixed with high titer BA i.d. }\end{array}$ \\
\hline
\end{tabular}




\begin{tabular}{|c|c|}
\hline $\begin{array}{l}\text { Days since } \\
\text { exploratory } \\
\text { laparotomy }\end{array}$ & Case treatment course \\
\hline 25 & $6 \mathrm{~L}$ of new ascites drained \\
\hline 39 & Blood transfusion (BT) $500 \mathrm{ml}$ \\
\hline 57 & Patient released for 10 days \\
\hline 67 & Admitted to continue immunotherapy \\
\hline 70 & $\begin{array}{c}\text { BT } 250 \mathrm{ml} \text { (remaining } 250 \mathrm{ml} \text { of blood } \\
\text { used for preparation of } 0.5 \mathrm{ml} \mathrm{ABC} \\
\text { doses) }\end{array}$ \\
\hline 72 & BA i.d weekly \\
\hline 106 & $\begin{array}{c}\text { CF } 50 \mathrm{mg} \text { tabl. daily for } 4 \text { weeks without } \\
\text { BA treatment }\end{array}$ \\
\hline 142 & End of CF treatment \\
\hline 147 & $8 \mathrm{~L}$ of ascites drained \\
\hline 157 & $3 \mathrm{~L}$ of ascites drained. $\mathbf{A B C}, 0.5 \mathrm{ml}$ i.d. \\
\hline 164 & $\begin{array}{c}\text { Small ascites only. } \mathbf{A B C}+\mathbf{B A} \text { i.d. to both } \\
\text { groins }\end{array}$ \\
\hline 192 & $\begin{array}{l}\text { Soft abdomen, no tumor or ascites } \\
\text { palpable. Vaginal Examination: no } \\
\text { palpable pelvic tumor }\end{array}$ \\
\hline
\end{tabular}

Table 2: Survey of patient 2 inoperable EOC treatment

\section{Comparisons of the Reported Inoperable Advanced EOCs Treatments}

The reported chemo-immunotherapy of inoperable EOCs in formerly untreated patients was not accompanied by any adverse events. It has been recently reported that the cyclophosphamide, in addition to its cytotoxic effect on cancer cells and leukocytes, improves the effectiveness of immunotherapy by immunomodulatory effects. Mechanisms include suppression of Treg cells, induction of homeostatic proliferation of $\mathrm{T}$ and $\mathrm{B}$ lymphocytes, facilitation of cancer infiltration by lymphocytes, and the emergence of a cytokine storm during recovery due to lymphocyte homeostatic proliferation [73]. Therefore, intermittent moderate cyclophosphamide treatment is an important component of effective immunotherapy. During cancer treatment, blood transfusions stimulate immune system reactivity against the alloantigens present on cancer cells [74], and provide unaltered circulating white blood cells, which may contribute to anticancer immunity.

It appears that the treatment of the first patient with an earlier application of cyclophosphamide, blood transfusions and bacterial toxins after exploratory laparotomy [72] was more successful, since it prevented the continuing development of ascites. Treatment with cyclophosphamide tablets alone without bacterial toxins in the second patient was not effective. Nevertheless, the later intradermal injection of $0.5 \mathrm{ml}$ of allogeneic buffy coat mixed with bacterial toxins to both groins without any additional treatment for one month thereafter, caused regression of ascites and abdominal and pelvic cavity tumor masses. The temporary use of bacterial toxins can prevent cancer progression, but they are not capable of causing ovarian cancer regression such as that seen during the treatment-free period after the combination of bacterial toxins with the cyclophosphamide and with allogeneic buffy coat.

The data reported originate from the former and recently discovered commentary not referenced in the PubMed on the detailed description of the clinical courses of patient 1 treatment [72], not available previously [14], and patient 2 treatment [72] reviewed for the first time here. The data suggest that sequential immunotherapy with cyclophosphamide eliminated antibodies blocking anticancer $\mathrm{T}$ cell effectors. Blood transfusions stimulated immune reactivity against cancer alloantigens, and bacterial toxins enhanced anticancer immune reactivity. These should be considered immediately after exploratory laparotomy (see Table 1). Intradermal injections of bacterial toxins, mixed with allogeneic buffy coats, should be given bilaterally close to lymph nodes draining the area with the primary cancer, i.e., the groin skin in EOCs. The described chemo-immunotherapy should incorporate several weeks of a treatment-free interval, when immunotherapy stops the cancer progression and the modulated immune system with enhanced anticancer reactivity becomes capable to reject primary cancer cells and their metastases without being subsequently interferenced.

The patients with advanced (inoperable) EOCs considered for these treatments should be in a relatively good condition without cachexia and with normal values of the red and white blood cells. This treatment might also be applicable for other epithelial cell malignancies, e.g., advanced colorectal cancers, and possibly some nonepithelial malignancies. What remains unresolved is an effective avoidance of frequently recurring EOCs, since the prevention of EOC relapses has been unavoidable, and remains problematic at the present time. Continuous stimulation of the patients' own immune system anticancer reactivity, and reactivity against cancer stem cells in particular, the goal of this proposed approach could improve outcomes.

\section{Long Lasting Cancer Survival Depends on Effective Prevention of Cancer Relapses}

One medication that appears to have potential to decrease the risk of cancer and improve cancer survival is oral metformin [75]. 
Metformin use has a protective effect for recurrences of ovarian and endometrial cancers [76]. It inhibitions ovarian CSCs [77,78]. It selectively kills CSCs that resist chemotherapy and cause cancer relapses [79].

An additional option is the consumption of the raw shiitake mushrooms [80-83]. They stimulate immune system mediated regression of cancer cells [84]. The active anticancer component of shiitake is thermolabile beta-glucan lentinan [85], which causes toxic shiitake dermatitis [86]. To prevent shiitake dermatitis, shiitake mushrooms are to be consumed after prolonged cooking [87], which, however, degrades the thermolabile lentinan. Lentinan exhibits marked anticancer and antimetastatic effects in numerous tumor/host systems, and inhibits development of chemical and viral carcinogenesis [88]. It also stimulates macrophage cytotoxicity against metastatic cancer cells [89], and increases survival of cancer patients when combined with chemotherapy [90]. Recurrent metastatic ovarian cancer regressed without chemotherapy, when the immunotherapy was followed by three applications of 2 mg lentinan every two weeks [91].

An otherwise untreated rectal cancer resolved after a severe dermatitis caused by consumption of an uncooked larger raw shiitake mushroom. Weekly consumption of a single larger raw shiitake mushroom in salads prevented any malignant recurrence over the next 25 years, without subsequent episodes of dermatitis [14]. During the last 14 years this is also accompanied by consumption of $1 \mathrm{~g}$ Metformin ER twice daily for the treatment of type II diabetes. The emergence of the skin dermatitis after initial consumption of the raw shiitake mushroom resembles the emergence of erysipelas after injection of Coley toxins, which have caused regression of epithelial cancers and soft tissue sarcomas [57].

These observations show that chemo-immunotherapy with cyclophosphamide causing depletion of endogenous antibodies blocking $\mathrm{T}$ cells, sensitization of the immune system against alloantigens of cancer cells, and enhancement of immune system reactivity by bacterial toxins can be augmented with daily doses of metformin and weekly consumption of the raw shiitake mushroom. This should enable cancer regression and regeneration of the metastatically altered tissues, without need of a debulking cytoreductive surgery or treatment with the high doses of cytostatics in advanced EOCs, and possibly other cancers. If unavailable, the Adnexba toxins use could be replaced by utilization of the BCG vaccine, which has been reported to have the therapeutic and prophylactic anticancer effects [63]. Continuing daily metformin and weekly shiitake mushroom consumptions after cancer regression may be followed by a long lasting prevention of recurrences, and weekly shiitake consumptions will be without an emergence of recurrent dermatitis and/or pruritus. The same may apply for the prevention of cancer relapses after regression induced by standard cytoreductive surgery and high dose chemotherapy.

\section{Conclusion}

Available data indicate that current cancer immunotherapy by immune checkpoint blockades may result in a high grade multiorgan alterations and patients' death. The causes of the immune adverse events lie in alteration of the natural immune system's role in tissue homeostasis. Cancer treatments with high doses chemotherapy frequently cause adverse events that alter the quality of patients' lives. During the last several decades the treatment of advanced EOCs by various approaches has not substantially improved the extended survival of patients. We propose effective immunotherapy of inoperable EOCs without adverse events. Continuous consumption of substances stimulating immune reactivity against cancer cells, such as combination of daily metformin with weekly lentinan, can stimulate cancer regression and prevent for long term cancer relapses. Carefully designed modern clinical trials on patients with advanced epithelial malignancies are needed to further investigate the potential of these therapies.

\section{Ethics Approval and Consent to Participate}

Not applicable. The treatment of patients was reported from the quoted article published in 1986, when regulations in this setting were not in force. Samples for immuno-histochemistry were obtained and processed between 1991 and 2009 by Antonin Bukovsky when working in the Department of Obstetrics and Gynecology of the Graduate School of Medicine in Knoxville, Tennessee, from the Department of Pathology, after annual approval by the Institutional Review Board, receipt of the Informed Consent signed by each patient, and agreement of the involved surgeon.

\section{References}

1. Editorial (2017) The double edge of cancer immunotherapy. Nat Med 23: 137.

2. Bertrand A, Kostine M, Barnetche T, Truchetet ME, Schaeverbeke T (2015) Immune related adverse events associated with anti-CTLA-4 antibodies: systematic review and meta-analysis. BMC Med 13: 211.

3. Lotfi-Jam K, Carey M, Jefford M, Schofield P, Charleson C, et al. (2008) Nonpharmacologic strategies for managing common chemotherapy adverse effects: a systematic review. J Clin Oncol 26: 5618-29.

4. McWhinney SR, Goldberg RM, McLeod HL (2009) Platinum neurotoxicity pharmacogenetics. Mol Cancer Ther 8: 10-6.

5. Weiderpass E, Tyczynski JE (2015) Epidemiology of Patients with Ovarian Cancer with and Without a BRCA1/2 Mutation. Mol Diagn Ther 19: 351-64.

6. Pisano C, Bruni GS, Facchini G, Marchetti C, Pignata S (2009) Treatment of recurrent epithelial ovarian cancer. Ther Clin Risk Manag 5: 421-6.

7. Papa A, Caruso D, Strudel M, Tomao S, Tomao F (2016) Update on Poly-ADP-ribose polymerase inhibition for ovarian cancer treatment. J Transl Med 14: 267.

8. Bukovsky A (2011) Immune maintenance of self in morphostasis of distinct tissues, tumor growth, and regenerative medicine. Scand J Immunol 73: 159-89.

9. Bukovsky A, Presl J, Zidovsky J, Mancal P (1983) The localization of Thy-1.1, MRC OX 2 and Ia antigens in the rat ovary and fallopian tube. Immunology 48: 587-96.

10. Bukovsky A, Michael SD, Presl J (1991) Cell-mediated and neural control of morphostasis. Med Hypotheses 36: 261-8. 
11. Bukovsky A, Caudle MR, Keenan JA, Upadhyaya NB, Van Meter S, et al. (2001) Association of mesenchymal cells and immunoglobulins with differentiating epithelial cells. BMC Developmental Biology 1: 11.

12. Terada T, Matsunaga Y (2001) S-100-positive nerve fibers in hepatocellular carcinoma and intrahepatic cholangiocarcinoma: an immunohistochemical study. Pathol Int 51: 89-93.

13. Ashraf S, Crowe R, Loizidou MC, Turmaine M, Taylor I, et al. (1996) The absence of autonomic perivascular nerves in human colorectal liver metastases. Br J Cancer 73: 349-59.

14. Bukovsky A (2016) Involvement of blood mononuclear cells in the infertility, age-associated diseases and cancer treatment. World J Stem Cells 8: $399-427$.

15. Lambolez F, Mayans S, Cheroutre H (2013) Lymphocytes: Intraepithelial. eLS. John Wiley \& Sons Ltd, Chichester, USA.

16. Shanklin WM (1951) Lymphocytes and lymphoid tissue in the human pituitary. Anat Rec 111: 177-91.

17. Winnock M, Garcia BM, Lukomska B, Huet S, Saric J, et al. (1995) Human liver-associated lymphocytes: an overview. J Gastroenterol Hepatol 10: S43-6.

18. Klein JR (2006) The immune system as a regulator of thyroid hormone activity. Exp Biol Med (Maywood) 231: 229-36.

19. Barrett TA, Gajewski TF, Danielpour D, Chang EB, Beagley KW, et al. (1992) Differential function of intestinal intraepithelial lymphocyte subsets. J Immunol 149: 1124-30.

20. Komori HK, Meehan TF, Havran WL (2006) Epithelial and mucosal gammadelta T cells. Curr Opin Immunol 18: 534-8.

21. Hirosako S, Goto E, Fujii K, Tsumori K, Hirata N, et al. (2009) Human bronchial intraepithelial T cells produce interferon-gamma and stimulate epithelial cells. Clin Exp Immunol 155: 266-74.

22. Macleod AS, Havran WL (2011) Functions of skin-resident gammadelta T cells. Cell Mol Life Sci 68: 2399-408.

23. Andrew W, Andrew NV (1945) Mitotic division and degeneration of lymphocytes within the cells of intestinal epithelium in the mouse. Anat Rec 93: 251-77.

24. Bukovsky A (2015) Novel methods of treating ovarian infertility in older and POF women, testicular infertility, and other human functional diseases. Reprod Biol Endocrinol 13: 10.

25. Conrad FJ, Rice JS, Cambier JC (2007) Multiple paths to loss of anergy and gain of autoimmunity. Autoimmunity 40: 418-24.

26. Mueller DL (2010) Mechanisms maintaining peripheral tolerance. Nat Immunol 11: 21-7.

27. Mathe G (1997) Immunity aging. I. The chronic perduration of the thymus acute involution at puberty? Or the participation of the lymphoid organs and cells in fatal physiologic decline? Biomed Pharmacothera 51: 49-57.

28. Milo R, Phillips R (2015) Cell Biology by the Numbers. Taylor \& Francis Inc, USA.

29. Cuk M, Radosevic-Stasic B, Milin C, Kirgin M, Rukavina D (1987) Lymphoid system as a regulator of morphostasis and hormonal regulation of these functions. Annals of the New York Academy of Sciences 496: 104-7.

30. Nakamoto N, Cho H, Shaked A, Olthoff K, Valiga ME, et al. (2009) Synergistic reversal of intrahepatic HCV-specific CD8 T cell exhaustion by combined PD-1/ CTLA-4 blockade. PLoS Pathog 5: e1000313.

31. Lee TH, Paglieroni T, Ohto H, Holland PV, Busch MP (1999) Survival of donor leukocyte subpopulations in immunocompetent transfusion recipients: frequent long-term microchimerism in severe trauma patients. Blood 93: 3127-39.

32. Lee TH, Paglieroni T, Utter GH, Chafets D, Gosselin RC, et al. (2005) High-level long-term white blood cell microchimerism after transfusion of leukoreduced blood components to patients resuscitated after severe traumatic injury. Transfusion 45: 1280-90.

33. Bloch EM, Jackman RP, Lee TH, Busch MP (2013) Transfusion-associated microchimerism: the hybrid within. Transfus Med Rev 27: 10-20.

34. Bukovsky A, Caudle MR, Wimalasena J, Keenan JA, Elder RF (2001) The role of the host-tumor interface and cell hybridization in invasive cancer. Med Hypotheses 57: 729-35.

35. Lindahl KF (1979) Anomalous H-2 antigens on tumour cells. Nature 280: 105-6.

36. Ferrone S, Pellegrino MA, Callahan GN (1980) Human and murine tumours: changes in cell surface structures coded by the major histocompatibility complex region. J Immunogenet 7: 71-9.

37. Larsen JF (1970) Electron microscopy of nidation in the rabbit and observations on the human trophoblastic invasion. In: Hubinnot PO, Leroy F, Robyn C, Leleux P, editors. Ovo-implantation, Human Gonadotropins and Prolactin. S. Karger, Basel 38-51.

38. Buttery LD, McCarthy A, Springall DR, Sullivan MH, Elder MG, et al. (1994) Endothelial nitric oxide synthase in the human placenta: regional distribution and proposed regulatory role at the feto-maternal interface. Placenta 15: 257-65.

39. Denekamp J (1984) Vascular endothelium as the vulnerable element in tumours. Acta Radiol Oncol 23: 217-25.

40. Shabo I, Svanvik J (2011) Expression of macrophage antigens by tumor cells. Adv Exp Med Biol 714: 141-50.

41. Yuan J, Zhang D, Wang L, Liu M, Mao J, et al. (2013) No evidence for neo-oogenesis may link to ovarian senescence in adult monkey. Stem Cells 31: 2538-50.

42. Bukovsky A (2015) Novel methods of treating ovarian infertility in older and POF women, testicular infertility, and other human functional diseases. Reprod Biol Endocrinol 13: 10.

43. Tureci O, Sahin U, Zwick C, Koslowski M, Seitz G, et al. (1998) Identification of a meiosis-specific protein as a member of the class of cancer/testis antigens. Proc Natl Acad Sci USA 95: 5211-6.

44. Mantha S, Sarasohn D, Ma W, Devlin SM, Chi DS, et al. (2015) Ovarian vein thrombosis after debulking surgery for ovarian cancer: epidemiology and clinical significance. Am J Obstet Gynecol 213: 208-4.

45. Bukovsky A (2017) Novel Immunological Aspects for the Treatment of Age-induced Ovarian and Testicular Infertility, Other Functional Diseases, and Early and Advanced Cancer Immunotherapy. In: Schatten H, editor. Human Reproduction: Updates and New Horizons. Wiley, Hoboken 143-204.

46. van de WM, Sancho E, Verweij C, de LW, Oving I, et al. (2002) The beta-catenin/TCF-4 complex imposes a crypt progenitor phenotype on colorectal cancer cells. Cell 111: 241-50.

47. Morrison SJ, Kimble J (2006) Asymmetric and symmetric stem-cell divisions in development and cancer. Nature 441: 1068-74.

48. Ashraf S, Loizidou M, Crowe R, Turmaine M, Taylor I, et al. (1997) Blood vessels in liver metastases from both sarcoma and carcinoma lack perivascular innervation and smooth muscle cells. Clin Exp Metastasis 15: 484-98.

49. Zhang S, Balch C, Chan MW, Lai HC, Matei D, et al. (2008) Identification and characterization of ovarian cancer-initiating cells from primary human tumors. Cancer Res 68: 4311-20. 
50. Burgos-Ojeda D, Rueda BR, Buckanovich RJ (2012) Ovarian cancer stem cell markers: prognostic and therapeutic implications. Cancer Lett 322 : 1-7. 51. Zhan Q, Wang C, Ngai S (2013) Ovarian cancer stem cells: a new target for cancer therapy. Biomed Res Int 2013: 916819.

52. Shah MM, Landen CN (2014) Ovarian cancer stem cells: are they real and why are they important? Gynecol Oncol 132: 483-9.

53. Garson K, Vanderhyden BC (2015) Epithelial ovarian cancer stem cells: underlying complexity of a simple paradigm. Reproduction 149: R59-70.

54. Lupia M, Cavallaro U (2017) Ovarian cancer stem cells: still an elusive entity? Mol Cancer 16: 64.

55. Drouin V, Viguie F, Debesse B (1993) Near-haploid karyotype in a squamous cell lung carcinoma. Genes Chromosomes Cancer 7: $209-12$.

56. McCarthy EF (2006) The toxins of William B. Coley and the treatment of bone and soft-tissue sarcomas. Iowa Orthop J 26: 154-8.

57. Richardson MA, Ramirez T, Russell NC, Moye LA (1999) Coley toxins immunotherapy: a retrospective review. Altern Ther Health Med 5: $42-7$.

58. Sinkovics JG, DiSaia PJ, Rutledge FN (1970) Tumour immunology and evolution of the placenta. Lancet 2: 1190-1.

59. Hellstrom I, Hellstrom KE, Sjogren HO, Warner GA (1971) Serum factors in tumor-free patients cancelling the blocking of cell-mediated tumor immunity. Int J Cancer 8: 185-91.

60. Steele G, Sjogren HO, Ankerst J (1974) The effects of cyclophosphamide on in vitro correlates of tumor immunity. Int J Cancer 14: 743-52.

61. Currie GA (1970) Active immunotherapy with Corynebacterium parvum and chemotherapy in murine fibrosarcomas. Br Med J 1: 541-4.

62. Cohen IR, Globerson A, Feldman M (1971) Rejection of tumor allografts by mouse spleen cells sensitized in vitro. J Exp Med 133: 821-33.

63. Simova J, Bubenik J (1975) Effect of prophylactic and therapeutic administration of BCG vaccine on growth of experimental sarcoma. Folia Biol 21: 329-33.

64. Chester C, Dorigo O, Berek JS, Kohrt H (2015) Immunotherapeutic approaches to ovarian cancer treatment. J Immunother Cancer 3: 7.

65. Coleman RL, Monk BJ, Sood AK, Herzog TJ (2013) Latest research and treatment of advanced-stage epithelial ovarian cancer. Nat Rev Clin Oncol 10: 211-24.

66. Baldwin LA, Huang B, Miller RW, Tucker T, Goodrich ST, et al. (2012) Ten-year relative survival for epithelial ovarian cancer. Obstet Gynecol 120: 612-8.

67. Littman DR (2015) Releasing the Brakes on Cancer Immunotherapy. Cell 162: 1186-90.

68. Gaillard SL, Secord AA, Monk B (2016) The role of immune checkpoint inhibition in the treatment of ovarian cancer. Gynecol Oncol Res Pract 3: 11.

69. Bukovsky A (1975) Immunological aspects of neoplasia. Cesk Gynekol 40: 464-6.

70. Kveton J (1972) Bacterinum adnexitidicum SEVAC in the treatment of inflammation of the female genitalia. Cesk Gynekol 37: 36-8.

71. Hellstrom I, Hellstrom KE, Sjogren HO, Warner GA (1971) Serum factors in tumor-free patients cancelling the blocking of cell-mediated tumor immunity. Int J Cancer 8: 185-91.

72. Bukovsky A, Presl J (1986) How to continue in the finding an effective treatment of cancer? Cesk Gynekol 51: 568-77.

73. Ziccheddu G, Proietti E, Moschella F (2013) The Janus face of cyclophosphamide: A sterile inflammatory response that potentiates cancer immunotherapy. Oncoimmunology 2: e25789.

74. Bukovsky A, Presl J (1985) Allosensitization in tumor therapy and prophylaxis, and in female contraception--a prospect for clinical use. Med Hypotheses 16: 241-51.

75. Evans JM, Donnelly LA, Emslie-Smith AM, Alessi DR, Morris AD (2005) Metformin and reduced risk of cancer in diabetic patients. BMJ 330 : $1304-5$.

76. Febbraro T, Lengyel E, Romero IL (2014) Old drug, new trick: repurposing metformin for gynecologic cancers? Gynecol Oncol 135: 614-21.

77. Kim TH, Suh DH, Kim MK, Song YS (2014) Metformin against cancer stem cells through the modulation of energy metabolism: special considerations on ovarian cancer. Biomed Res Int 2014: 132702.

78. Zhang R, Zhang P, Wang H, Hou D, Li W, et al. (2015) Inhibitory effects of metformin at low concentration on epithelial-mesenchymal transition of CD44(+) CD117(+) ovarian cancer stem cells. Stem Cell Res Ther 6: 262.

79. Hirsch HA, Iliopoulos D, Tsichlis PN, Struhl K (2009) Metformin selectively targets cancer stem cells, and acts together with chemotherapy to block tumor growth and prolong remission. Cancer Res 69: 7507-11.

80. Bomford R, Moreno C (1977) Mechanism of the anti-tumour effect of glucans and fructosans: a comparison with C. parvum. Br J Cancer 36: 41-8.

81. Kidd PM (2000) The use of mushroom glucans and proteoglycans in cancer treatment. Altern Med Rev 5: 4-27.

82. Hazama S, Watanabe S, Ohashi M, Yagi M, Suzuki M, et al. (2009) Efficacy of orally administered superfine dispersed lentinan (beta-1,3-glucan) for the treatment of advanced colorectal cancer. Anticancer Res 29: 2611-7.

83. Avinash J, Vinay S, Jha K, Das D, Goutham BS, et al. (2016) The Unexplored Anticaries Potential of Shiitake Mushroom. Pharmacogn Rev 10: 100-4.

84. Vetvicka V, Vetvickova J (2014) Immune-enhancing effects of Maitake (Grifola frondosa) and Shiitake (Lentinula edodes) extracts. Ann Transl Med 2: 14.

85. Dai X, Stanilka JM, Rowe CA, Esteves EA, Nieves C, et al. (2015) Consuming Lentinula edodes (Shiitake) Mushrooms Daily Improves Human Immunity: A Randomized Dietary Intervention in Healthy Young Adults. J Am Coll Nutr 34: 478-87.

86. Mendonca CN, Silva PM, Avelleira JC, Nishimori FS, Cassia FF (2015) Shiitake dermatitis. An Bras Dermatol 90: $276-8$.

87. Boels D, Landreau A, Bruneau C, Garnier R, Pulce C, et al. (2014) Shiitake dermatitis recorded by French Poison Control Centers - new case series with clinical observations. Clin Toxicol 52: 625-8.

88. Suzuki M, Takatsuki F, Maeda YY, Hamuro J, Chihara G (1994) Antitumor and immunological activity of lentinan in comparison with LPS. Int J Immunopharmacol 16: 463-8.

89. Ladanyi A, Timar J, Lapis K (1993) Effect of lentinan on macrophage cytotoxicity against metastatic tumor cells. Cancer Immunol Immunother 36: 123-6.

90. Ina K, Kataoka T, Ando T (2013) The use of lentinan for treating gastric cancer. Anticancer Agents Med Chem 13: 681-8.

91. Fujimoto K, Tomonaga M, Goto S (2006) A case of recurrent ovarian cancer successfully treated with adoptive immunotherapy and lentinan. Anticancer Res 26: 4015-8. 


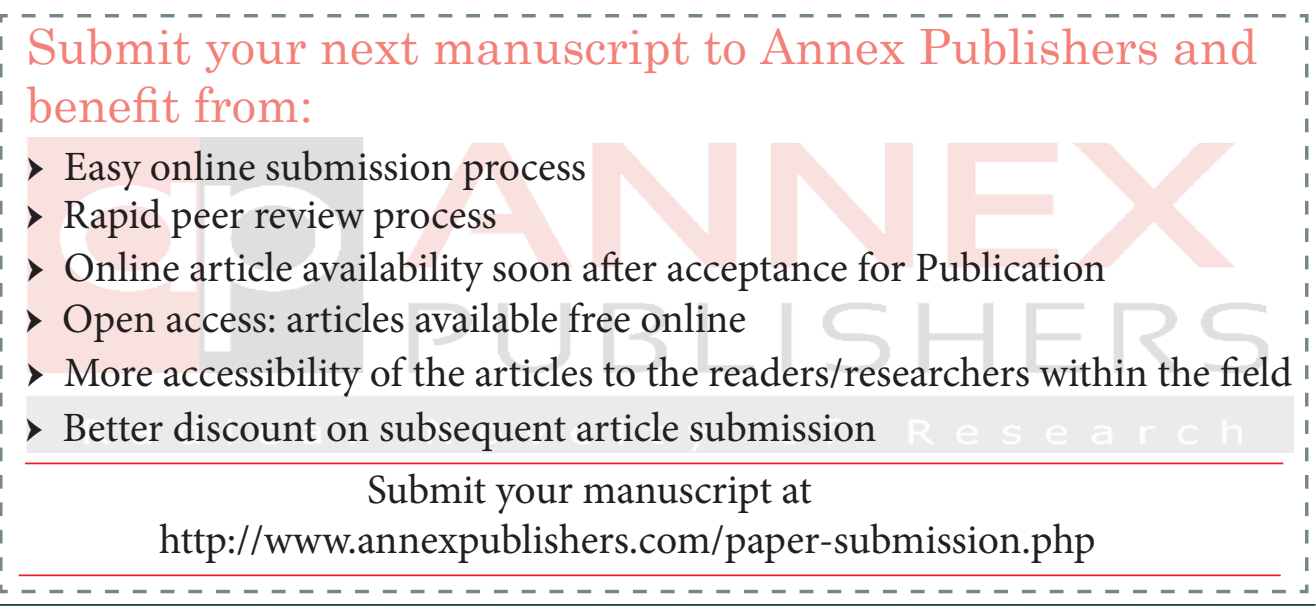

